\title{
Have Your Cake and Eat it Too? Cointegration and Dynamic Inference from Autoregressive Distributed Lag Models
}

\author{
Andrew Q. Philips*
}

March 27, 2017

Keywords: time series, cointegration, error-correction, dynamic modeling Running Header: Have Your Cake and Eat it Too?

\footnotetext{
*aphilips@pols.tamu.edu or andrew.philips@colorado.edu. I would like to thank Lorena Barberia, Allyson Benton, Harold Clarke, Peter Enns, Nathan Favero, Eric Guntermann, Mark Pickup, Joe Ura, B. Dan Wood, and participants of the Texas A\&M methodology brownbag lunches. Special thanks goes to Soren Jordan, Paul Kellstedt, and Guy D. Whitten. Despite this helpful advice, any errors and omissions remain my own.
} 


\begin{abstract}
:
Although recent articles have stressed the importance of testing for unit-roots and cointegration in time series analysis, practitioners have been left without a straightforward procedure to implement this advice. I propose using the autoregressive distributed lag model and bounds cointegration test as an approach to dealing with some the most commonly encountered issues in time series analysis. Through Monte Carlo experiments I show that this procedure performs better than existing cointegration tests under a variety of situations. I illustrate how to implement this strategy with two step-by-step replication examples. To further aid users, I have designed software programs in order to test and dynamically model the results from this approach.
\end{abstract}

Replication Materials: The data, code, and any additional materials required to replicate all analyses in this article are available on the American Journal of Political Science Dataverse within the Harvard Dataverse Network, at: http://dx.doi.org/10.7910/DVN/MPQQC0.

Word Count: Manuscript 8,164 (Word), 8,140 (wordcounter.net). 
Recent work in the time series literature has stressed the importance of testing for unit roots as well as the existence of long-run relationships - or cointegrationbetween variables. ${ }^{1}$ Since the presence or absence of each of these characteristics ultimately determines the appropriate model, failure to perform such pretesting makes spurious inferences more likely. Even with existing tools designed to identify unitroots and test for cointegration, short series, the weak power of statistical tests, and the dangers of overfitting make pretesting time series data particularly problematic. Although recent articles have helped to identify these issues (Grant and Lebo 2016; Keele, Linn and Webb 2016), users have been left without a straightforward solution about how to deal with such problems. ${ }^{2}$

I propose using the autoregressive distributed lag model and associated bounds testing procedure (ARDL-bounds) developed by Pesaran, Shin and Smith (2001) as a comprehensive approach to model specification and cointegration testing. Depending on the results of the cointegration test, this strategy absolves users from having to distinguish between stationary (henceforth $\mathrm{I}(0)$ ) and first-order non-stationary (I(1)) regressors. This is an advantage since unit-root testing is difficult in short series, and introduces, "a further degree of uncertainty into the analysis" (Pesaran, Shin and Smith 2001, p. 289). The ARDL-bounds procedure involves:

${ }^{1}$ Covariance stationary series exhibit constant mean, variance, and covariance. A linear combination of two or more first-order non-stationary series that yields a stationary series is said to be cointegrating.

${ }^{2}$ Grant and Lebo (2016) provide two solutions, including the one discussed herein. However, their discussion is brief. 
1. Ensuring the dependent variable is $\mathrm{I}(1)$.

2. Ensuring the independent variables are not explosive or higher orders of integration than $\mathrm{I}(1)$.

3. Estimating the ARDL model in error-correction form, and ensuring there is no autocorrelation.

4. Performing the bounds test for cointegration. Three possibilities result: (a) all regressors are I(1) and cointegrating (b) all regressors are I(0) - by definition, they cannot cointegrate - or (c) indeterminate. An indeterminate result may still find cointegration among some of the independent variables, although further testing and re-specification (in Step 3) is required.

Surprisingly, while this method is popular in other fields (over 5,300 cites on Google Scholar as of September 2016), it has been cited and implemented only twice among the American Political Science Review, American Journal of Political Science, Journal of Politics, and Political Analysis: Dickinson and Lebo (2007) and Grant and Lebo (2016).

Four contributions stand out in this article. First, I discuss why an additional time series procedure is necessary, given recent debates about the role of errorcorrection models (Esarey 2016; Grant and Lebo 2016; Helgason 2016; Keele, Linn and Webb 2016). Second, I use Monte Carlo experiments to compare the performance of the ARDL-bounds cointegration test against existing alternatives, under a variety of scenarios that practitioners typically encounter. I also examine how well 
the model recovers substantively interesting effects, such as long-run multipliers or adjustment parameters. Third, I demonstrate the utility of the ARDL-bounds approach and the merits of dynamic interpretation through two replications. Finally, I conclude with guidelines for implementing this procedure, and introduce software programs designed to help practitioners with cointegration testing and exploring the substantive implications of their results.

\section{Unit Roots and Cointegration in Time Series}

Consider a general autoregressive distributed lag $\operatorname{ARDL}(p, q)$ model where a series, $y_{t}$, is a function of a constant term, $\alpha_{0}$, past values of itself stretching back $p$ periods, contemporaneous and lagged values of an independent variable, $x_{t}$, of lag order $q$, and an independent, identically distributed error term:

$$
y_{t}=\alpha_{0}+\sum_{i=1}^{p} \alpha_{i} y_{t-i}+\sum_{j=0}^{q} \beta_{j} x_{t-j}+\varepsilon_{t}, \quad \varepsilon_{t} \sim N\left(0, \sigma^{2}\right)
$$

The data-generation process for the dependent and independent variables determines how Equation 1 is estimated. If variables on both the left- and right-hand side are $\mathrm{I}(0)$, they will exhibit constant mean, variance, and covariance, and the $\operatorname{ARDL}(p, q)$ shown in Equation 1 may be used. ${ }^{3}$ Since additional lags may induce multicollinearity, lag order restrictions are often imposed. A common restriction is the $\operatorname{ARDL}(1,1)$

${ }^{3}$ The stationarity condition for $y_{t}$ is given as $\left|\sum_{i=1}^{p} \alpha_{i}\right|<1$. Such variables are said to be covariance stationary. 
model:

$$
y_{t}=\alpha_{0}+\alpha_{1} y_{t-1}+\beta_{0} x_{t}+\beta_{1} x_{t-1}+\varepsilon_{t}
$$

The contemporaneous effect of $x_{t}$ on $y_{t}$ is given by $\beta_{0}$. The magnitude of $\alpha_{1}$ informs us about the "memory" of $y_{t}$ (De Boef and Keele 2008). Assuming $0<\alpha_{1}<1$, larger values indicate that movements in $y_{t}$ take longer to dissipate. ${ }^{4}$ The long-run effect (or long-run multiplier) is the total effect that a change in $x_{t}$ has on $y_{t}$. It is given as $\kappa_{1}=\frac{\left(\beta_{0}+\beta_{1}\right)}{\left(1-\alpha_{1}\right)}$, and its variance is typically approximated using the delta method.

The generalized error-correction model (GECM) may also be used if all variables are $\mathrm{I}(0)$; the most common form is the one-step GECM:

$$
\Delta y_{t}=\alpha_{0}+\alpha_{1}^{*} y_{t-1}+\beta_{0} \Delta x_{t}+\beta_{1}^{*} x_{t-1}+\varepsilon_{t}
$$

where the first-difference of $y_{t}$ is a function of a constant term, $\alpha_{0}$, its own lag, $y_{t-1}$, the first-difference of $x_{t}$ and its lag, $x_{t-1}$, and an i.i.d. error term, $\varepsilon_{t}$. Although the GECM is algebraically equivalent to the $\operatorname{ARDL}(1,1)$ model, interpretation changes. Contemporaneous effects of a change in $x_{t}$ on $y_{t}$ are still given by $\beta_{0}$. The rate of adjustment, or the speed at which the total effect of a change of $x_{t}$ accumulates in $y_{t}$, is given by $\alpha_{1}^{*}$. It is used in calculating the long-run multiplier, $\kappa_{1}=-\frac{\beta_{1}^{*}}{\alpha_{1}^{*}}$. Although obtaining variance estimates of the short-run effect is straightforward, the variance around $\kappa_{1}$ must be approximated using the Bewley transformation or the

${ }^{4}$ Values of $\alpha_{1}$ greater than one suggest an explosive series or model misspecification. Values less than zero suggest the series is over-correcting or oscillating; this is rare in the social sciences. 
delta method (De Boef and Keele 2008).

The GECM is also ideal for when the dependent and independent variables are I(1) and cointegrating. In our bivariate example, if there exists some linear combination of the two $\mathrm{I}(1)$ series that results in a stationary series, they are said to be cointegrating. Testing is often performed using the Engle-Granger "two-step" approach (Engle and Granger 1987), which involves regressing $y_{t}$ on $x_{t}$ :

$$
y_{t}=\kappa_{0}+\kappa_{1} x_{t}+z_{t}
$$

If both variables are $\mathrm{I}(1)$, there exists one cointegrating relationship if the residuals in Equation $4, z_{t}$, are stationary. ${ }^{5}$ More generally, a sufficient condition to use an error-correction model is if all variables are I(1) and cointegrating. ${ }^{6}$

Even if both series are I(1), there may not always be an underlying cointegrating relationship between them. Practitioners often conflate re-equilibration with errorcorrection, and fail to test for cointegration (Grant and Lebo 2016). ${ }^{7}$ Even if $x_{t}$ and $y_{t}$ are $\mathrm{I}(1)$, without cointegration, there cannot be a long-run relationship between them, since (rewriting Equation 4) the linear combination of the series, $z_{t}=\left(y_{t-1}-\right.$

${ }^{5}$ The is true for any $k$ series, which can have up to $k-1$ cointegrating relationships.

${ }^{6}$ This condition is sufficient but not necessary; one could use other models (e.g. first-differences). I focus on I(1) series since higher orders of integration are rare in political science, although this excludes the possibility of multi-cointegration (Enders 2010, pp. 380-382).

${ }^{7}$ While cointegrating relationships can be estimated using GECMs, estimating GECMs does not necessarily mean two or more series are cointegrated. 
$\left.\kappa_{0}-\kappa_{1} x_{t-1}\right)$ will not be stationary. If all variables are $\mathrm{I}(1)$ but not cointegrating, the series can only be analyzed in first-differences, since there still may exist a short-run relationship.

The recommendations above are straightforward in theory. In practice, identifying the correct model is non-trivial. For one, unit-root tests often have size distortions and low power in small samples, making it difficult to determine whether a variable is $\mathrm{I}(0)$ or I(1) (Maddala and Kim 1998; Choi 2015). This difficulty is compounded since users must test each variable in order to use models such as the GECM. Series may be so highly autoregressive (near-integrated) that testing procedures cannot distinguish it from an I(1) series (De Boef and Granato 1997). Moreover, series may be fractionally integrated. While some scholars argue that these are common in political science (Box-Steffensmeier and Smith 1998; Lebo, Walker and Clarke 2000; Grant and Lebo 2016), others remain skeptical (Pickup 2009; Keele, Linn and Webb 2016). ${ }^{8}$ In other words, with short series (less than 100), we are often at the mercy of our tests, and risk choosing models that are not reflective of the characteristics of our data.

As recent work has shown, many scholars have overlooked the crucial steps of testing for unit roots and cointegration (Grant and Lebo 2016). Others find that complex model specifications tend to overfit and perform poorly in small samples (Keele, Linn and Webb 2016; Esarey 2016). While these important contributions have identified potential problems, they leave users without a clear and easy-to-

${ }^{8}$ Helgason (2016) and Esarey (2016) investigate treating data as fractionally integrated versus I(1) through Monte Carlo simulations. 
implement solution. As I show in the next section, a procedure already exists that greatly eases unit-root testing, includes a test for cointegration, and is simple to estimate. Moreover, when combined with dynamic simulations, these models can provide additional substantive interpretations.

\section{A Comprehensive Approach to Time Series Analysis}

The autoregressive distributed lag (ARDL) model and associated bounds test of Pesaran, Shin and Smith (2001) is already popular in economics, but relatively unknown in political science. It is ideal for four reasons. First, although we may suspect that all regressors are I(1), an initial model can be estimated without having to rely on unit-root testing to distinguish between $\mathrm{I}(0)$ or $\mathrm{I}(1)$ regressors. Restrictions on the independent variables can then be imposed to avoid spurious conclusions of cointegration. Second, the one-step procedure for the initial cointegration test is similar to the GECM, making it easy to estimate. Third, the cointegration test is often straightforward to interpret. Fourth, this framework provides a comprehensive approach for practitioners.

The ARDL-bounds approach is shown in schematic form in Figure 1. ${ }^{9}$ As shown in step $a$, users must first establish if the dependent variable is $\mathrm{I}(1)$. To mitigate difficulties with unit-root testing, users should employ a suite of unit-root tests and account for the possibility of periodicity, drift, and deterministic trends. If the

${ }^{9}$ For brevity I do not consider fractionally integrated relationships. I discuss strategies for handling these data in the Supplemental Materials. 
dependent variable is stationary, then cointegration is not possible, and any $\mathrm{I}(1)$ regressors must be first-differenced (step $f$ ). After ensuring that all independent variables are stationary ( $\operatorname{step} c$ ), we must also check that no autocorrelation remains in the residuals (step $i$ ). As shown by step $h$ in Figure 1, if there is autocorrelation we can incorporate lags of the dependent and independent variables, or lagged first-differences if a regressor is I(1). Lag structures are typically chosen based on theoretical expectations about the data-generation process, and by minimizing information criteria such as AIC or SBIC. If no autocorrelation remains, the resulting ARDL model is one where all variables are $\mathrm{I}(0)$, as shown in step $j$, a version of which was shown in Equation 1. There is no need to check for cointegration, since all variables are stationary.

[Figure 1 about here]

If the dependent variable is $\mathrm{I}(1)$, there may be cointegration. As shown in step $b$ in Figure 1, we do not have to establish whether the regressors are I(0) or I(1); we of course suspect I(1), since we are testing for cointegration. However, we must ensure that there are no explosive series, seasonal unit-roots, or series higher than I(1) in any of the variables. Violation of these conditions invalidates the testing procedure. Independent variables that are non-stationary of higher orders than I(1) must be differenced (step $d$ ) before moving forward. ${ }^{10}$

Next, estimate the ARDL model in error-correction form (step e). Recall that a cointegrating relationship between an $\mathrm{I}(1)$ dependent variable, $y_{t}$, and a weakly

\footnotetext{
${ }^{10}$ This excludes the possibility of multi-cointegration (Enders 2010, pp. 380-382).
} 
exogenous $\mathrm{I}(1)$ regressor, $x_{t}$, can be written as: ${ }^{11}$

$$
y_{t}=\kappa_{0}+\kappa_{1} x_{t}+z_{t}
$$

If the residuals, $z_{t}$, are stationary, there is evidence of cointegration. ${ }^{12}$ In order to estimate this model, $z_{t-1}$ is included in the following GECM:

$$
\Delta y_{t}=\alpha_{0}-\alpha\left(z_{t-1}\right)+\beta_{0} \Delta x_{t}+\varepsilon_{t}
$$

rewritten, it becomes:

$$
\Delta y_{t}=\alpha_{0}-\alpha\left(y_{t-1}-\hat{\kappa}_{0}-\hat{\kappa}_{1} x_{t-1}\right)+\beta_{0} \Delta x_{t}+\varepsilon_{t}
$$

The unrestricted error-correction model referred to by Pesaran, Shin and Smith (2001, p. 293) forms the basis of the ARDL-bounds procedure. It involves multiplying through by $-\alpha$ and collecting terms in Equation 7:

$$
\Delta y_{t}=\alpha_{0}^{*}+\theta_{0} y_{t-1}+\theta_{1} x_{t-1}+\beta_{0} \Delta x_{t}+\varepsilon_{t}
$$

${ }^{11}$ In the context of cointegration, a variable is weakly exogenous if it, "does not respond to the discrepancy from the long-run equilibrium relationship" (Enders 2010, p. 407).

${ }^{12}$ If a deterministic trend was suspected in $y_{t}$, Equation 5 becomes: $y_{t}=\hat{\kappa}_{0}+\hat{\gamma} T+$ $\hat{\kappa}_{1} x_{t}+z_{t}$. We could also exclude the drift term, $\hat{\kappa}_{0}$, or account for a deterministic trend in $x_{t}$. 
where $\alpha_{0}^{*}=\left(\alpha_{0}+\alpha \hat{\kappa}_{0}\right)$ and $\theta_{0}=-\alpha$. As with the GECM, the coefficient on the lagged value of $x_{t}, \theta_{1}=\alpha \hat{\kappa}_{1}$, can be combined with the lagged dependent variable to extract the long-run multiplier. The contemporaneous effect is given by $\beta_{0}$. Since residual autocorrelation may be problematic, up to $q$ lags of the first-difference of the independent variables, and up to $p$ lags of the first-difference of the dependent variable, may be included in order to purge serial autocorrelation from $\varepsilon_{t}$ (steps $g$ and k) (Pesaran, Shin and Smith 2001, p. 299). Theory and information criteria should be used to specify lag structure, and autocorrelation tests used to ensure white-noise residuals. The resulting model appears as:

$$
\Delta y_{t}=\alpha_{0}^{*}+\theta_{0} y_{t-1}+\theta_{1} x_{t-1}+\sum_{i=1}^{p} \alpha_{i} \Delta y_{t-i}+\sum_{j=0}^{q} \beta_{j} \Delta x_{t-j}+\varepsilon_{t}
$$

After estimating the ARDL-bounds model in Equation 9, and ensuring whitenoise residuals (steps $g$ and $k$ ), the next step is to conduct the bounds test (step $n)$. It tests the null hypothesis of no cointegration between the dependent variable and any regressors included in the cointegrating equation (Pesaran, Shin and Smith 2001, pp. 294-295). Only regressors that enter into the equation in levels (e.g. $x_{t-1}$ ) in Equation 9 can (potentially) cointegrate with $y_{t}$. The bounds F-test consists of running a Wald- or F-test on the following restriction from Equation 9:

$$
H_{0}: \theta_{0}=\theta_{1}=0
$$

under the null hypothesis that no cointegrating relationship exists between $x_{t}$ and $y_{t}$. Rejecting $H_{0}$ indicates that there is a cointegrating relationship between the series. 
In addition to the F-test, a one-sided t-test may be used to test the null hypothesis that the coefficient on the lagged dependent variable is equal to zero: $H_{0}: \theta_{0}=0$. The alternative hypothesis is that $\theta_{0}<0$, which suggests cointegration. This is known as the bounds t-test.

The critical value bounds for the F- and t-statistics are non-standard, and depend on the number of regressors appearing in levels, as well as the restrictions placed on the intercept and trend. ${ }^{13}$ Asymptotic critical values for the t- and F-statistics can be found in Pesaran, Shin and Smith (2001, pp. 300-304), while small-sample critical values for the F-statistic can be found in Narayan (2005, pp. 1987-1990). No smallsample critical values are currently available for the t-test, so in small samples it should only be used for confirmatory purposes. Interpretation of the bounds test is illustrated in Figure 2. Three possibilities result:

\section{[Figure 2 about here]}

If the value of the F-statistic is lower than the stationary critical value, then we cannot reject the null hypothesis that there is no cointegrating relationship (step $q$ in Figure 1); in fact, we can conclude that all independent variables appearing in levels are stationary, without having to conduct any further unit-root testing. If this is

\footnotetext{
${ }^{13}$ Dummy variables may be included without compromising the asymptotic properties of the tests, as long as they tend towards zero as the series increases (Pesaran, Shin and Smith 2001, p. 307). The cointegration test does not account for the possibility of seasonal unit roots (Pesaran, Shin and Smith 2001, p. 291), or other forms of periodicity, so these should be pre-whitened out accordingly.
} 
the case, the final model specification is the first-difference of the dependent variable regressed on up to $l$ lags of the independent variables appearing in levels, as well as up to $p$ and $q$ lags of the first differences of the dependent and independent variables necessary to remove autocorrelation (step $r)$ :

$$
\Delta y_{t}=\alpha_{0}+\sum_{k=0}^{l} \delta_{k} x_{t-k}+\sum_{i=1}^{p} \alpha_{i} \Delta y_{t-i}+\sum_{j=0}^{q} \beta_{j} \Delta x_{t-j}+\varepsilon_{t}
$$

If the value of the F-statistic is higher than the $\mathrm{I}(1)$ critical value, not only are all series $\mathrm{I}(1)$, there also exists a cointegrating relationship between them. No further unit-root testing of the regressors is required, as shown by step $o$ in Figure 1. Evidence suggests that the resulting ARDL model in error-correction form is correctly specified, and that cointegration exists between the dependent variable and any independent variables appearing in levels.

If the F-statistic is between the stationary and I(1) critical values, the test is inconclusive. There could be a mix of stationary and I(1) regressors, and cointegration among the I(1) variables and the dependent variable may still exist. However, further testing is required. As shown by step $m$ in Figure 1, the next step is to conduct unit-root tests for each independent variable. Since I(0) variables cannot possibly have a cointegrating relationship with an I(1) dependent variable, they should only enter into the model in first-differenced form. ${ }^{14}$ After re-running the ARDL model in error-correction form (step e), conduct the bounds test for cointegration (step $n$ )

${ }^{14}$ Of course, $\mathrm{I}(0)$ series could still appear in levels in the final model specification without risking spurious regression. 
on the remaining I(1) regressors. If a conclusive result is reached, no further testing is required. If the test is still inconclusive, the next step is to start excluding combinations of $\mathrm{I}(1)$ regressors from appearing in the cointegrating equation (having a $\boldsymbol{\theta}$ coefficient in Equation 9), and repeat steps $e$ and n. If, after iterating through the possible combinations of independent variables, there is still no conclusive result from the bounds test, then we can conclude no cointegration. Since short-run effects between I(1) variables may still exist, the final model can be estimated in first-differences.

Evaluating the t-statistic is exactly the opposite as the F-statistic; if the value of the t-statistic is lower than the $\mathrm{I}(1)$ critical value, than we can reject the null hypothesis of no cointegrating relationship. If the value of the t-statistic falls above the $\mathrm{I}(0)$ critical value, then we cannot reject the null hypothesis. Just as with the F-statistic, if the critical value falls between the bounds, the test is inconclusive, and more precise testing of the regressors is necessary. That is to say, we would next use unit-root testing to isolate out only the I(1) variables and iterate through them as needed in order to conclude either cointegration (step o) or all $\mathrm{I}(0)$ regressors (step $q)$.

\section{Monte Carlo Evidence}

The key component to the ARDL-bounds procedure is the cointegration test, since it ultimately determines our conclusions about the relationships between variables. How does its performance compare to existing approaches? To evaluate this, I present 
two Monte Carlo experiments. The first focuses on finding evidence of cointegration when it does not exist (Type I error), while the second investigates failing to detect cointegration when it exists (Type II error).

To evaluate the ability of the bounds cointegration test to avoid Type I error, I generated an I(1) dependent variable, $y_{t}$, for series of length $T=35,50,80 .{ }^{15}$ Next, four independent variables, $x_{k t}$ (where $\left.k=1,2,3,4\right)$, were generated. These were completely unrelated to $y_{t}$, or to one another:

$$
\begin{array}{r}
y_{t}=y_{t-1}+\eta_{t} \\
x_{k t}=\phi_{k} x_{k t-1}+v_{k t}
\end{array}
$$

The stochastic components $\eta_{t}$ and $v_{k t}$ are i.i.d. and independent from each other. As discussed earlier, detection of stationary variables is difficult in short series. To see the consequences of erroneously including an I(0) regressor when all other variables are I(1), I allow the autoregressive process for $x_{1 t}, \phi_{1}$, to vary from 0.0 to 1.0 by increments of 0.20. All other independent variables are I(1) (i.e., $\phi_{k}=1 \quad \forall k \neq 1$ ). Next, I ran the ARDL-bounds model:

$\Delta y_{t}=\alpha_{0}+\theta_{0} y_{t-1}+\theta_{1} x_{1 t-1}+\cdots+\theta_{k} x_{k t-1}+\sum_{i=1}^{p} \alpha_{i} \Delta y_{t-i}+\sum_{j=0}^{q_{1}} \beta_{1 j} \Delta x_{1 t-j}+\cdots+\sum_{j=0}^{q_{k}} \beta_{k j} \Delta x_{k t-j}+\varepsilon_{t}$

The number of lagged first-differences of $y_{t}$ and each $x_{k t}$ to include in Equation 14 was

${ }^{15}$ To mitigate issues involving initial conditions (Balke and Fomby 1997), I created a burn-in period of $T=100$ for all simulations. 
determined via SBIC for each of the 500 simulations conducted for all combinations of $T, k$, and $\phi_{1 x} \cdot{ }^{16}$ After estimating Equation 14, an F-test of the null hypothesis that $\theta_{0}=\theta_{1}=\cdots=\theta_{k}=0$ was conducted for each simulation. The resulting statistic was compared against the associated critical values of the bounds test from Narayan (2005, p. 1988). Since these series were independently generated, evidence of cointegration (a F-statistic greater than the $\mathrm{I}(1)$ critical value) is an incorrect rejection of the null hypothesis and thus a form of Type I error. ${ }^{17}$

I compare the performance of the bounds test to two other procedures. I included the Engle-Granger two-step procedure by implementing an augmented Dickey-Fuller unit-root test on the residual series, $z_{t}$, from the cointegrating equation: $y_{t}=\kappa_{0}+$ $\kappa_{1} x_{1 t}+\cdots+\kappa_{k} x_{k t}+z_{t} \cdot{ }^{18}$ I also used the Johansen procedure for cointegration to test for the existence of a single cointegrating relationship, using both the multiple trace testing procedure as well as the number of cointegrating ranks as chosen by

${ }^{16} \mathrm{~A}$ restriction of $p, q_{k} \leq 3$ was placed on the maximum number of lag lengths in Equation 14 for $T=35$, and 4 for $T=50,80$. This restriction appeared to be an ideal trade-off between overfitting and ensuring white-noise residuals; I discuss issues regarding overfitting in the Supplemental Materials.

${ }^{17} \mathrm{~F}$-statistics between the $\mathrm{I}(0)$ and $\mathrm{I}(1)$ bound, or below the $\mathrm{I}(0)$ bound, were treated as avoiding Type I error. Treating them as Type I error does not change the substantive results, as shown in the Supplemental Materials.

${ }^{18}$ The same lag restrictions were placed on the additional augmenting lags of $\Delta y_{t-i}$ needed to remove autocorrelation, as determined by minimizing SBIC. Critical values are from Mackinnon (1994). 
minimizing SBIC (Johansen 1995). ${ }^{19}$ Although cointegration tests are only supposed to be run on all-I(1) series, the purpose of this Monte Carlo experiment is to evaluate test performance when a stationary regressor is erroneously included, given that in small series an autoregressive I(0) variable may be indistinguishable from an I(1) series.

The results from the first Monte Carlo experiment are shown in Figure 3. The level of autoregression, $\phi_{1}$, in the single stationary series - $x_{1 t}$-is on the horizontal axis. The proportion of simulations finding evidence of cointegration is on the vertical axis; higher values indicate Type I error. When there are only 35 observations, it is clear that the bounds test is the only cointegration procedure that comes close to the conventional five percent rejection rate (shown by the thin black line). As the number of independent variables increases (each column shows the number of $k$ regressors), all tests tend to have increased Type I error. For instance, when there are four regressors, we find spurious evidence of cointegration about 60 percent of the time when using the Engle-Granger test; surprisingly, its high rate of Type I error does not change as $T$ increases. This finding underscores recent work on overfitting in short time series (Helgason 2016; Keele, Linn and Webb 2016). Despite this, the bounds test excels at successfully failing to reject the null hypothesis of no cointegration under all scenarios. Only the Johansen test appears to have the same low rate of Type I error, but only when the level of autoregression in $x_{1 t}$ approaches a unit-root process.

${ }^{19}$ Lag-order selection was the same as the Engle-Granger procedure. Results of $r \neq 1$ were recorded as no evidence of Type I error. 
[Figure 3 about here]

The performance of the bounds test is notable in a number of ways. Not surprisingly, I find evidence that it, along with other cointegration tests, perform poorly in small samples. However, this is only when the length of the series is small and the number of regressors large. Even then, the rate of Type I error using the bounds test is often half that of the other cointegration tests, and remains robust to erroneously including an $\mathrm{I}(0)$ regressor. Only the Johansen-BIC test has a similar level of Type I error, but only when all variables are at or near I(1). The fact that the performance of the bounds test is barely affected by autoregression indicates that it is a good test for cointegration in small samples; this is exactly when we might erroneously include an I(0) variable. Finally, while the Engle-Granger procedure is robust to autoregression in a single regressor, it has much larger Type I error as the number of regressors increase. Taken together, this evidence suggests that the bounds cointegration test has lower Type I error than other tests, and remains robust to short series, multiple regressors, and erroneously including stationary regressors.

I next explore the likelihood that the bounds test fails to detect cointegration when it exists (Type II error). As before, I vary the number of regressors and the number of observations. However, now the independent variables cointegrate with 
the dependent variable: ${ }^{20}$

$$
\begin{array}{r}
x_{k t}=x_{k t-1}+v_{k t} \\
u_{t}=0.75 u_{t-1}+\eta_{t} \\
y_{t}=0.25 x_{1 t}+\cdots+0.25 x_{k t}+u_{t}
\end{array}
$$

The errors $v_{k t}$ and $\eta_{t}$ are independent. This data-generation process yields an adjustment parameter of -0.25 and a long-run multiplier of 0.25 for each of the $k$ independent variables. The cointegration tests are the same as in the previous experiment, and conducted on 1,000 simulations across each combination of observations and regressors.

The results of the second experiment are shown in Figure 4. Each bar depicts the proportion of cointegrating relationships for a particular cointegration test, across each combination of observations and regressors. Higher values correspond with a lower rate of Type II error. For all tests, as the length of the series increases, Type II error decreases. In addition, as the number of cointegrating regressors increase, the Engle-Granger test correctly identifies cointegration at a greater rate than other tests. The bounds test has the largest Type II error rate when $T=35$, although this improves sharply as the series lengthen. In addition, the proportion of simulations correctly identifying cointegration varies significantly across tests; the Engle-Granger procedure has between one-third and one-half the rate of Type II error as the bounds test, and the bounds test has about one-half the Type II error as the Johansen tests.

\footnotetext{
${ }^{20} \mathrm{~A}$ proof of this is in the Supplemental Materials.
} 
[Figure 4 about here]

A number of important findings stand out from these two experiments on cointegration. The bounds test has the lowest Type I error across all scenarios; moderate Type I error (20 percent) occurs only when there are four regressors and 50 observations or less. While the bounds test is largely unaffected, the Johansen test tends to experience a rapid increase in Type I error rates when an I(0) regressor is included. Although the Engle-Granger test has the lowest Type II error rates, the bounds test tends to perform better than the Johansen tests in all scenarios, except for a single regressor or short series.

In the Supplemental Materials I conduct eight additional Monte Carlo experiments. These include varying the adjustment parameter and long-run multiplier, using fractionally (co)integrated series, and examining the percentage of time a given cointegration test correctly or incorrectly diverges from the other three cointegration tests. I also examine the ability of the GECM and ARDL-bounds models to recover substantively interesting effects (e.g., short- and long-run effects, or the adjustment parameter). Many of the findings are consistent with those above; interested readers are directed to the brief summary in Table 1 in the Supplemental Materials.

Taken together, the Monte Carlo results suggest that the bounds test offers an ideal compromise between Type I and Type II error. Given calls for more conservative cointegration tests (Grant and Lebo 2016), the bounds test seems the prudent choice since it strongly avoids spurious cointegration, yet can still identify true cointegrating 
relationships, at least for weakly exogenous regressors. ${ }^{21}$ I show two applications of this approach below.

\section{Application I: Kelly and Enns (2010)}

Kelly and Enns (2010) examine how income inequality affects public mood liberalism and support for welfare policy. The authors find that in the long run, increases in inequality are associated with the public becoming more conservative and less supportive of welfare. They find no evidence that policy liberalism, income inequality, unemployment, or inflation have any effect on public mood in the short run. There are two reasons to believe these results may be suspect. First, the number of observations is small. Second, although Kelly and Enns perform unit-root testing on the dependent variable, the authors make no mention of testing the regressors.

I replicated their model of public support for welfare policy. ${ }^{22}$ Results from their GECM are shown in Table 1, Model 1. First, I ensured that the dependent variable is $\mathrm{I}(1)$ (see step $a$ in the Figure 1 schematic). Results from five unit-root tests are shown in Table 2. While we can reject the null hypothesis of an I(1) series using the augmented Dickey-Fuller test, more powerful ones such as the DF-GLS, or ERS test, find evidence of a unit-root process. ${ }^{23}$ Although the KPSS test also provides

${ }^{21}$ Were the regressors endogenous, methods such as the Johansen approach should be used.

${ }^{22}$ Table 1, Model 4, p. 864 in their article.

${ }^{23}$ The augmented Dickey-Fuller and Phillips-Perron tests suffer from size distortions and weak power, and are often outperformed by the ERS and DF-GLS tests 
mixed evidence, we can tentatively confirm that the data-generating process of the dependent variable is I $(1){ }^{24}$

[Table 1 about here]

[Table 2 about here]

After ensuring that all regressors are first-order non-stationary or less (step $b$ in Figure 1), I then estimated the ARDL model in error-correction form (step $e$ ). ${ }^{25}$ Using SBIC, I found that the lag structure in the original model used by Kelly and Enns (2010) was optimal, given the data. This specification produced white-noise residuals, as evidenced by a battery of post-estimation diagnostics. Thus, the ARDLbounds model shown in Model 2 in Table 1 is identical to the original ECM in Model 1.

Since the model appears to be dynamically stable, we next use the bounds test to identify if a cointegrating relationship exists between support towards welfare policy, policy liberalism, and income inequality (step $n$ in Figure 1). An Ftest that the parameters on the variables appearing in lagged levels-Welfare ${ }_{t-1}$, Policy Liberalism $_{t-1}$, and Income Inequality $y_{t-1}$ - are jointly equal to zero, yields an (Maddala and Kim 1998, pp. 98-103; Choi 2015, pp. 37-54; Enders 2010, pp. 234$237)$.

${ }^{24}$ I examine the consequences of concluding stationarity in the Supplemental Materials. Although the final model differs, the substantive results remain unchanged.

${ }^{25}$ Unit-root tests of the first-difference of policy liberalism and inequality rejected the I(2) null hypothesis; results are in the Supplemental Materials. 
F-statistic of 4.15. Although Narayan (2005) provides the small-sample critical values necessary to evaluate this statistic, these are also available in Stata and $\mathrm{R}$ using the programs pssbounds and pss, respectively (Philips 2016b; Jordan and Philips 2016). The critical values for 33 observations and two regressors are a lower stationary bound of 4.183 and an upper I(1) bound of 5.333. Strictly speaking, the F-statistic is below the stationary lower bound, so we might conclude that all regressors are stationary (step $q$ in Figure 1). However, given that the test result was so close to the $\mathrm{I}(0)$ lower bound of the test, we may want to treat the result as inconclusive, which means that further testing is be needed. ${ }^{26}$

Although the results of the cointegration test were borderline inconclusive with both policy liberalism and income inequality, a single regressor may still cointegrate with welfare policy mood. The next step is to test that the regressors are $\mathrm{I}(1)$, since any $\mathrm{I}(0)$ regressor can easily be excluded from the cointegrating equation (step $m$ in Figure 1). Unit-root testing (available in the Supplemental Materials) indicated that both policy liberalism and income inequality are $\mathrm{I}(1)$.

Since unit-root testing did not narrow down which series should not appear in the cointegrating equation, I estimated two different models (step $n$ ). In Model 3, I test to see if only income inequality has a cointegrating relationship with public mood towards welfare. Therefore, policy liberalism does not appear in levels in Model 3. In order to produce white-noise residuals (steps $g$ and $k$ ), the lagged first-difference

\footnotetext{
${ }^{26}$ Moreover, the one-sided bounds t-test on the significance of the lagged dependent variable, -3.46, falls between the asymptotic upper I(0) and lower I(1) critical bounds of -2.86 and -3.53 , respectively; this supports the "inconclusive" decision.
} 
of policy liberalism was included. Because Model 3 reflects a data-generating process where only income inequality is cointegrating, evidence of cointegration in Model 3 would indicate that income inequality, not policy liberalism, is cointegrating with public mood towards welfare. An F-test of the significance of the lagged variables in Model 3 yields an F-statistic of 1.72. Since this is below the critical value of 5.290 for the $\mathrm{I}(0)$ lower bound and 6.175 for the $\mathrm{I}(1)$ upper bound, we can conclude that income inequality and public mood towards welfare are not cointegrating.

Next, I test to see if only policy liberalism has a cointegrating relationship with public mood towards welfare. Therefore, in Model 4 income inequality does not appear in levels. To produce white-noise residuals, one lag of the first difference of income inequality was included. For Model 4, a rejection of the null hypothesis using the bounds test would suggest that policy liberalism, not income inequality, is cointegrating with public mood towards welfare. An F-test of the significance of the lagged variables yields an F-statistic of 3.57. Since this falls below the $\mathrm{I}(0)$ critical value of 5.290 (as well as the upper I(1) critical value, 6.175), we can conclude that policy liberalism and public mood towards welfare are not cointegrating.

Since neither income inequality or policy liberalism on their own appear to have a cointegrating relationship with welfare policy mood-nor do the three variables altogether, as found in Model 2-we can conclude that there is no cointegration ( $\operatorname{step} q$ ). Since the two independent variables may still affect public mood towards welfare in the short-run, we may run a model of first-differences (step $r$ ). This is shown in Model 5 in Table 1. The results indicate that income inequality and policy liberalism do not have a statistically significant effect on the public's feelings towards 
welfare policy in the short-run, a similar conclusion to what Kelly and Enns find. ${ }^{27}$

This replication is informative since it shows how one should proceed, given an inconclusive bounds test result. After finding that all regressors were I(1), I proceeded to iterate through two different models, excluding one of the regressors from appearing in the cointegrating equation in Models 3 and 4. Since there was no evidence for cointegration when isolating out income inequality and policy liberalism, the final model was one of first-differences, since the error-correction framework is no longer appropriate.

While suggestive, this replication does not completely overturn the findings of Kelly and Enns. Short series introduce a large amount of uncertainty into cointegration tests, so it seems reasonable that different researchers might come to different conclusions. $^{28}$ Overall, given the best available methods, there appear to be null findings in their model of public mood towards welfare. ${ }^{29}$

${ }^{27}$ What differs is that the authors find evidence of a long-run effect, whereas the ARDL-bounds approach does not.

${ }^{28}$ The Monte Carlo results show that while the bounds test tends to avoid spurious conclusions of cointegration in small samples, it also tends to have a high rate of false-negatives; thus, it is hard to ascertain whether their result holds.

${ }^{29}$ However, I find evidence of cointegration using this same approach when examining Kelly and Enns' other dependent variable — public mood liberalism — as detailed in the Supplemental Materials. 


\section{Application II: Volscho and Kelly (2012)}

Volscho and Kelly (2012) use a GECM to probe the determinants of the rise in top income shares in the US from 1949 to 2008. I examine their power resource model, which investigates if the share of income of the top one percent is determined by political and institutional factors. Results from their original model are shown in Table 3, Model 1. As Volscho and Kelly find, increases in Democratic strength in Congress, union membership, and the presence of divided government, tend to decrease the share of income held by the super-rich, but only in the long-run. In contrast, Democratic presidents have no effect.

\section{[Table 3 about here]}

To implement the ARDL-bounds procedure, I first ensured that the dependent variable, Top 1\% Share, was I(1), as shown in Table 4 (step $a$ in Figure 1). After confirming that the regressors are $\mathrm{I}(1)$ or less (step $b$ ), I used SBIC to assist in lag selection for the ARDL model in error-correction form, the result of which is shown in Model 2 ( $\operatorname{step} e$ ). Although the authors may have had theoretical reasons to use the "dead-start" GECM, I find instead that a model of contemporaneous short-run effects has a lower SBIC. While theory should always guide model specification, users must ensure that the residuals are white-noise in order to run the bounds test; in this example, both the dead-start and standard GECM yielded white-noise residuals. ${ }^{30}$

\section{[Table 4 about here]}

\footnotetext{
${ }^{30}$ Therefore, one could use the bounds test on either model.
} 
Since Model 2 contains white-noise residuals, we can move onto cointegration testing using the bounds test (step $n$ in Figure 1). An F-test of the joint significance of the five lagged variables (the four regressors plus the dependent variable) yields an F-statistic of 5.02. Critical values for 61 observations and four regressors are 3.068 and 4.274 for the lower and upper bounds, respectively. Since the F-statistic is greater than the $\mathrm{I}(1)$ upper bound, we can conclude that there is a cointegrating relationship (step $o$ ). As further confirmation we can use the bounds t-test; the tstatistic on the lagged dependent variable is -4.01 , which is below the critical value of the $\mathrm{I}(1)$ lower bound (-3.99). Thus, there is strong evidence that all four regressors are cointegrating with the dependent variable.

The largest difference between Volscho and Kelly's original model and the ARDLbounds model is the significance of the short-run effect of a Democratic president. To see if this leads to different conclusions than the ones made by the authors, in the Supplemental Materials I use dynamic simulations to help interpret how changes in one regressor affects the dependent variable over time. Model-based dynamic simulations are growing in popularity in political science (King, Tomz and Wittenberg 2000; Williams and Whitten 2012), and are especially valuable for examining complex model specifications such as autoregressive relationships with interactions (Williams and Whitten 2011), or dynamic compositional dependent variables (Philips, Rutherford and Whitten 2016, 2015). The ARDL-bounds procedure's lag structure makes it a prime candidate for dynamic simulations. Using the program dynpss to create dynamic simulations of the ARDL-bounds model (Philips 2016a), I find that in the short run, moving from a Republican to a Democratic president increases the income 
concentration of the top one percent. However, this effect loses statistical significance after four years, is not statistically significantly different from the predictions using Volscho and Kelly's GECM, and the long run effect is nearly zero. ${ }^{31}$ These results are available in the Supplemental Materials.

In summary, I find evidence for cointegration in the power resources model of Volscho and Kelly. While the ARDL-bounds model had slight specification differences, the substantive findings do not change, as evidenced by dynamic simulations. Institutional and political factors may affect the income share of the top one percent, but only in the long-run.

\section{Discussion and Conclusion}

The two examples above represent a variety of situations that the ARDL-bounds approach is designed to handle. For the Kelly and Enns (2010) replication, I find no evidence of cointegration. Using the steps outlined in Figure 1, I find no evidence that policy liberalism and income inequality affect welfare policy mood in the long- or short-run. For the Volscho and Kelly (2012) replication, I find evidence of cointegration; these findings support the authors' conclusions about the long-run effect of institutions and politics on the concentration of income of the top one percent. In the Supplemental Materials I also replicate Ura (2014), and find evidence of cointegration.

\footnotetext{
${ }^{31}$ This is confirmed analytically by calculating the long-run multiplier, which is 0.36 and is not statistically significantly different from zero.
} 
Although the examples above are representative of most situations practitioners are likely to encounter, I briefly review how users should proceed, given their own theoretically-specified model:

1. Unit-root testing of the dependent variable. If the dependent variable is I(1), proceed with the ARDL in error-correction form. ${ }^{32}$

2. Ensure that no independent variables are of an order of integration higher than I(1). The main advantage of the bounds approach is that users do not have to make difficult decisions between $\mathrm{I}(0)$ and $\mathrm{I}(1)$ regressors; the results of the bounds test informs us of these characteristics. However, users must ensure that no variables are integrated more than I(1), explosive, or contain seasonal unit-roots. ${ }^{33}$

3. Estimate the ARDL in error-correction form. Since the bounds testing procedure relies on white-noise residuals, add lags of the first-differences of the dependent variable and regressors as needed. Use theory and information criteria to aid in lag specification. Ensure that the residuals are white-noise.

4. Test the joint significance of all lagged variables appearing in levels using a Wald/F-test. Use small-sample critical values of the bounds test in Narayan

${ }^{32}$ If the dependent variable is $\mathrm{I}(0)$, it is not first-differenced, leading to a lagged dependent variable model as shown in the Figure 1 schematic.

${ }^{33}$ While the test statistics can be adjusted to account for deterministic trends in the dependent variable, it is advisable to identify and de-trend instead. 
(2005). As an auxiliary test, use the one-sided t-test of the lagged dependent variable using asymptotic critical values in Pesaran, Shin and Smith (2001).

5. If the results of the bounds test:

(a) Suggest cointegration: All variables appearing in levels appear to be I(1) and have a cointegrating relationship with the dependent variable.

(b) Suggest stationarity: All regressors appearing in levels are I(0) and cannot possibly be in a cointegrating relationship. A model of first-differences must be estimated since the variables may still affect the dependent variable in the short-run.

(c) Are inconclusive: Each regressor should be tested for a unit-root. Only I(1) variables can appear in levels in the error-correction model. Stationary variables may still appear in first-differences. ${ }^{34}$ Repeat Steps 3 and 4. If the resulting statistic is still inconclusive, combinations of variables appearing in levels may need to be tested. Continue testing until (5a) or (5b) reached.

6. Interpretation: Use dynamic simulations and analytical calculations for hypothesis testing.

While the ARDL-bounds procedure provides a comprehensive approach to modeling time series and testing for cointegration, it is not a remedy for all problems.

\footnotetext{
${ }^{34} \mathrm{I}(0)$ variables could appear in levels in the final model without risking spurious regression.
} 
First, like all time series models, it tends to perform poorly in small samples. As a precaution against overfitting, Keele, Linn and Webb (2016, p. 40) suggest a minimum of between 10 and 20 observations per parameter. ${ }^{35}$ However, as shown by Monte Carlo simulations, the bounds cointegration test tends to perform at least as well as other cointegration tests in small samples. Second, this single-equation model imposes a causal ordering and assumes weak exogeneity of the regressors (Pesaran, Shin and Smith 2001, p. 293), a disadvantage shared with GECMs. Users unwilling to impose a causal ordering should consider alternative methods such as vector error-correction models, which can account for multiple cointegrating relationships. Third, the cointegration test serves as a substitute for unit-root testing to distinguish between $\mathrm{I}(0)$ and $\mathrm{I}(1)$ regressors only when the test results fall outside of the critical bounds. Given an inconclusive test result, users must use unit-root tests on all regressors, and identify the stationary, I(1), and I(1)-and-cointegrating variables through an iterative process, as shown in the Kelly and Enns (2010) replication. Last, this procedure still requires balanced equations (Keele, Linn and Webb 2016; Grant and Lebo 2016); although stationary regressors can appear in levels in the final model, I(1) regressors that are not cointegrating cannot appear in levels in the final model without risk of spurious regression.

To aid in the use of this approach, this article has provided a step-by-step guide for practitioners, which can be used with any software package that contains unitroot, autocorrelation, and the F- and t-tests necessary for the bounds test (e.g., R, Stata, or EViews). In addition, in the Supplemental Materials I discuss software

\footnotetext{
${ }^{35}$ I address concerns about overfitting in the Supplemental Materials.
} 
programs in Stata and $\mathrm{R}$ designed to help users test for cointegration and create dynamic simulations. ${ }^{36}$

This article was motivated by a series of recent articles in the time series literature that stress the importance of careful unit-root and cointegration testing. To achieve this, I have advocated for the autoregressive distributed lag bounds approach. I have shown that the ARDL-bounds procedure starts with a theoretically-specified model and moves step-by-step to arrive at an informed conclusion. Through careful testing and model specification, the ARDL-bounds procedure is a powerful approach to a difficult problem in applied time series analysis.

\footnotetext{
${ }^{36}$ In Stata, these are pssbounds for displaying critical values of the bounds test and dynpss for creating dynamic simulations of the ARDL-bounds model (Philips 2016a,b). The pss package implements these commands in R (Jordan and Philips 2016).
} 


\section{References}

Balke, Nathan S and Thomas B Fomby. 1997. "Threshold cointegration." International Economic Review 38(3):627-645.

Box-Steffensmeier, Janet M and Renee M Smith. 1998. "Investigating political dynamics using fractional integration methods." American Journal of Political Science 42(2):661-689.

Choi, In. 2015. Almost all about unit roots: Foundations, developments, and applications. Cambridge University Press.

De Boef, Suzanna and Jim Granato. 1997. "Near-integrated data and the analysis of political relationships." American Journal of Political Science 41(2):619-640.

De Boef, Suzanna and Luke Keele. 2008. "Taking time seriously." American Journal of Political Science 52(1):184-200.

Dickinson, Matthew J and Matthew J Lebo. 2007. "Reexamining the growth of the institutional presidency, 1940-2000.” Journal of Politics 69(1):206-219.

Enders, Walter. 2010. Applied econometric time series. 3 ed. John Wiley and Sons.

Engle, Robert F and Clive WJ Granger. 1987. "Co-integration and error correction: representation, estimation, and testing." Econometrica 55(2):251-276.

Esarey, Justin. 2016. "Fractionally integrated data and the autodistributed lag model: Results from a simulation study." Political Analysis 24:42-49. 
Grant, Taylor and Matthew J. Lebo. 2016. "Error correction methods with political time series." Political Analysis 24:3-30.

Helgason, Agnar Freyr. 2016. "Fractional integration methods and short time series: Evidence from a simulation study." Political Analysis 24(1):59-68.

Johansen, Soren. 1995. Likelihood-based inference in cointegrated vector autoregressive models. Oxford University Press.

Jordan, Soren and Andrew Q Philips. 2016. "pss: R package to perform the bounds test for cointegration and create dynamic simulations." Available at: https://github.com/andyphilips/pss. R package version 1.3.9.

Keele, Luke, Suzanna Linn and Clayton M Webb. 2016. "Treating time with all due seriousness." Political Analysis 24:31-41.

Kelly, Nathan J and Peter K Enns. 2010. "Inequality and the dynamics of public opinion: The self-reinforcing link between economic inequality and mass preferences." American Journal of Political Science 54(4):855-870.

King, Gary, Michael Tomz and Jason Wittenberg. 2000. "Making the most of statistical analyses: Improving interpretation and presentation." American Journal of Political Science 44:347-361.

Lebo, Matthew J, Robert W Walker and Harold D Clarke. 2000. "You must remember this: Dealing with long memory in political analyses." Electoral Studies $19(1): 31-48$. 
MacKinnon, James G. 1994. "Approximate asymptotic distribution functions for unit-root and cointegration tests." Journal of Business and Economic Statistics $12(2): 167-176$.

Maddala, Gangadharrao S and In-Moo Kim. 1998. Unit roots, cointegration, and structural change. Cambridge University Press.

Narayan, Paresh Kumar. 2005. "The saving and investment nexus for China: Evidence from cointegration tests." Applied Economics 37(17):1979-1990.

Pesaran, M Hashem, Yongcheol Shin and Richard J Smith. 2001. "Bounds testing approaches to the analysis of level relationships." Journal of Applied Econometrics $16(3): 289-326$.

Philips, Andrew Q. 2016a. "dynpss: Stata module to dynamically simulate autoregressive distributed lag (ARDL) models." Available at: https://andyphilips.github.io/dynpss/.

Philips, Andrew Q. 2016b. "pssbounds: Stata module to conduct the Pesaran, Shin, and Smith (2001) bounds test for cointegration." Available at: http://andyphilips.github.io/pssbounds/.

Philips, Andrew Q, Amanda Rutherford and Guy D Whitten. 2015. "The dynamic battle for pieces of pie-Modeling party support in multi-party nations." Electoral Studies 39:264-274.

Philips, Andrew Q, Amanda Rutherford and Guy D Whitten. 2016. "Dynamic pie: 
A strategy for modeling trade-offs in compositional variables over time." American Journal of Political Science 60(1):268-283.

Pickup, Mark. 2009. "Testing for fractional integration in public opinion in the presence of structural breaks: A comment on Lebo and Young." Journal of Elections, Public Opinion and Parties 19(1):105-116.

Ura, Joseph Daniel. 2014. "Backlash and legitimation: Macro political responses to supreme court decisions." American Journal of Political Science 58(1):110-126.

Volscho, Thomas W and Nathan J Kelly. 2012. "The rise of the super-rich: Power resources, taxes, financial markets, and the dynamics of the Top 1 percent, 1949 to 2008." American Sociological Review 77(5):679-699.

Williams, Laron K and Guy D Whitten. 2011. "Dynamic simulations of autoregressive relationships." Stata Journal 11(4):577-588.

Williams, Laron K and Guy D Whitten. 2012. "But wait, there's more! Maximizing substantive inferences from TSCS models." The Journal of Politics 74(03):685-693. 


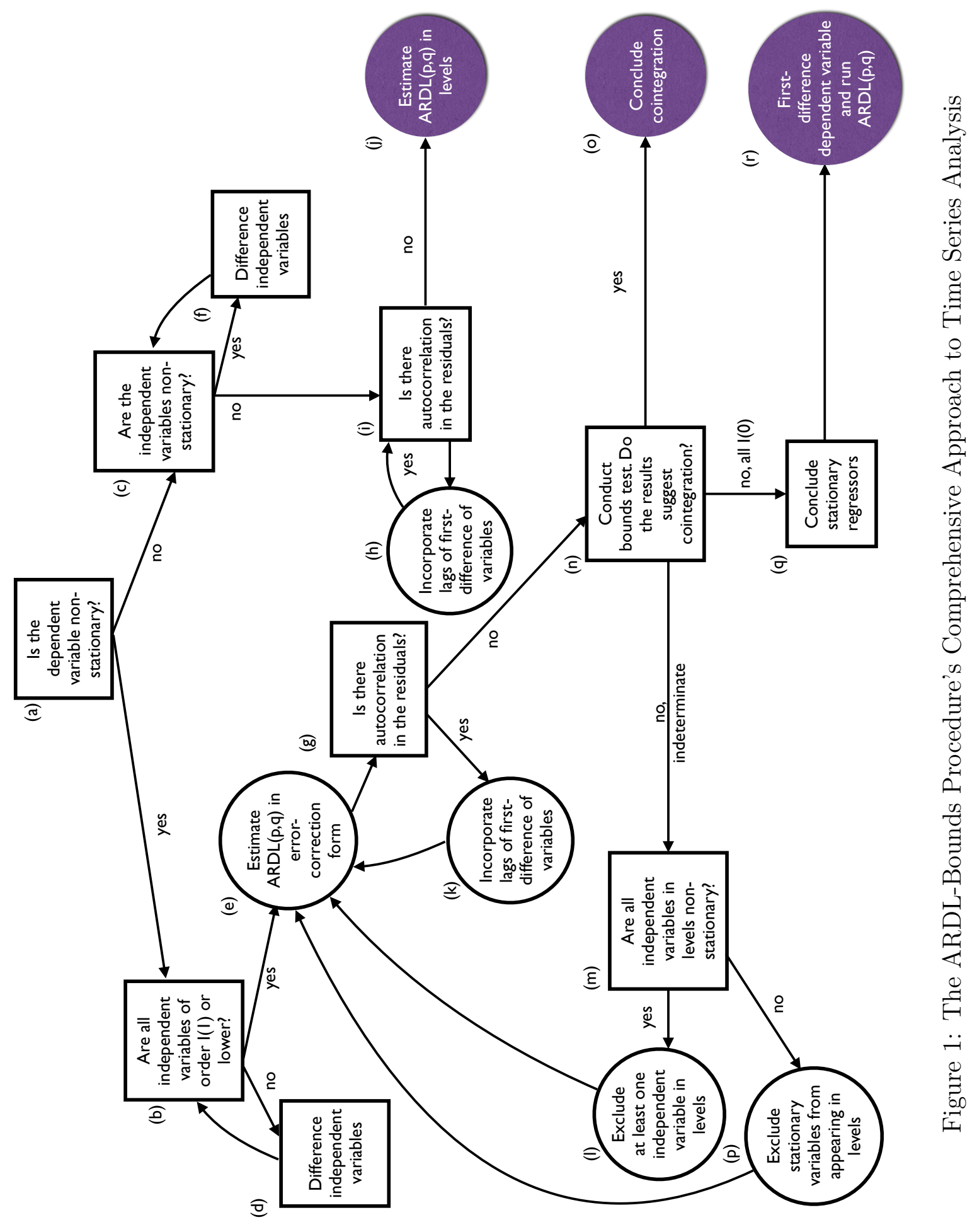




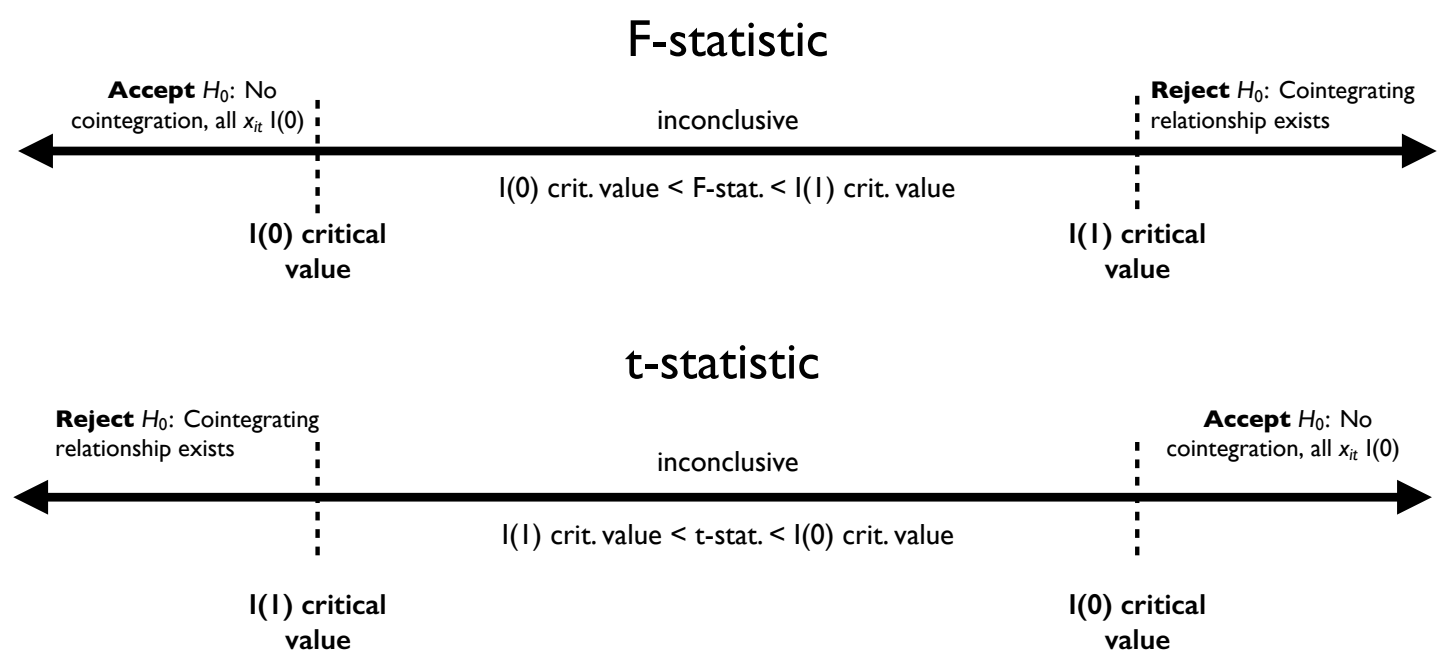

Figure 2: Bounds Test Statistics 

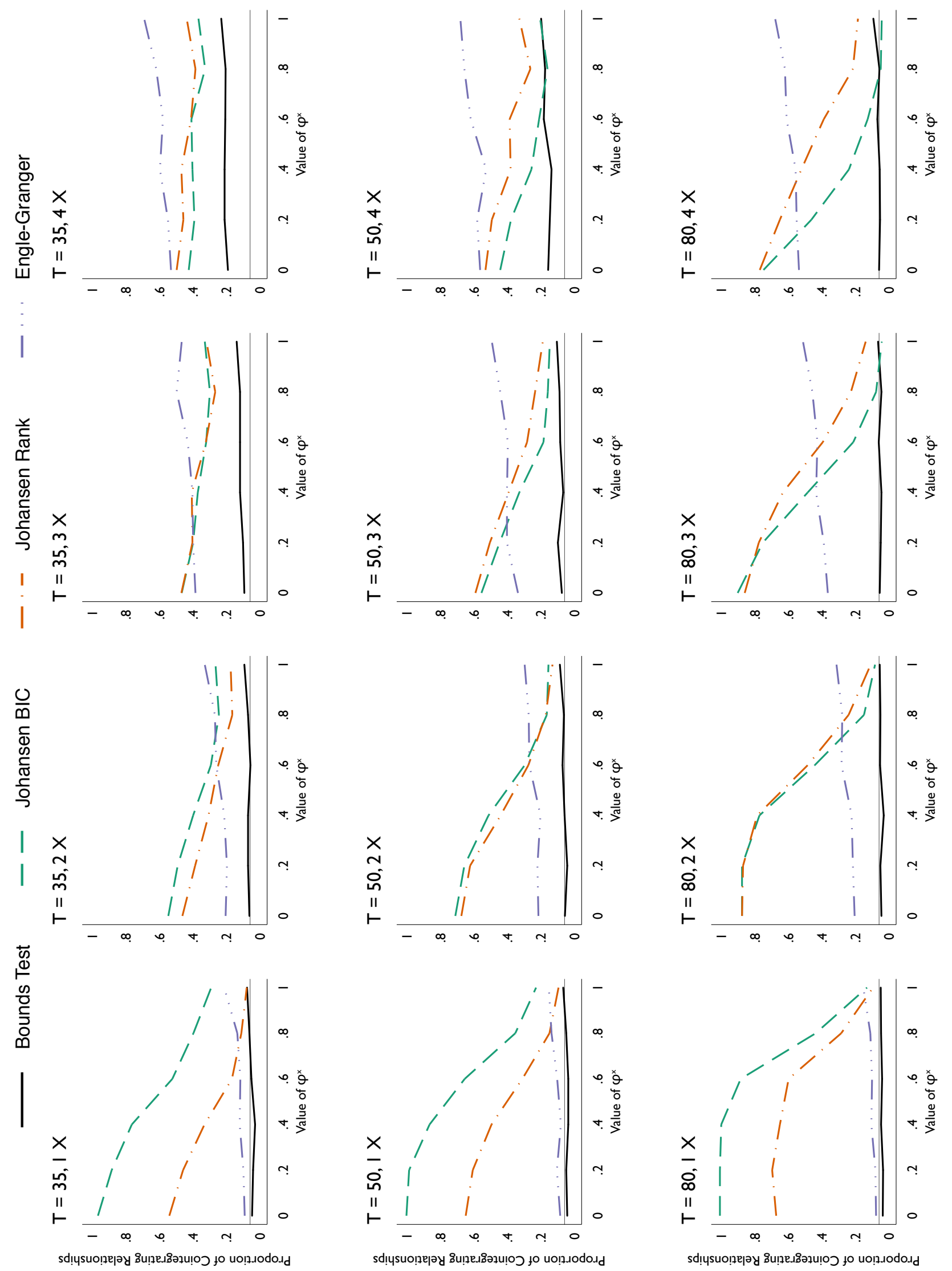

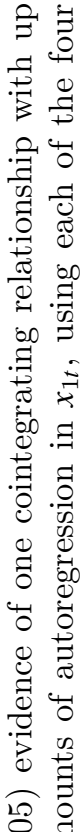

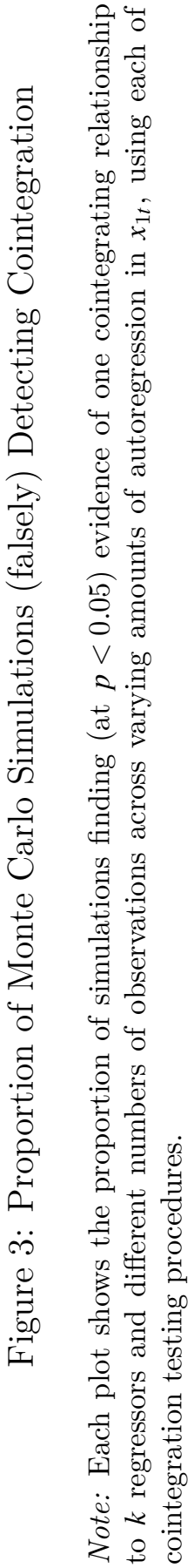



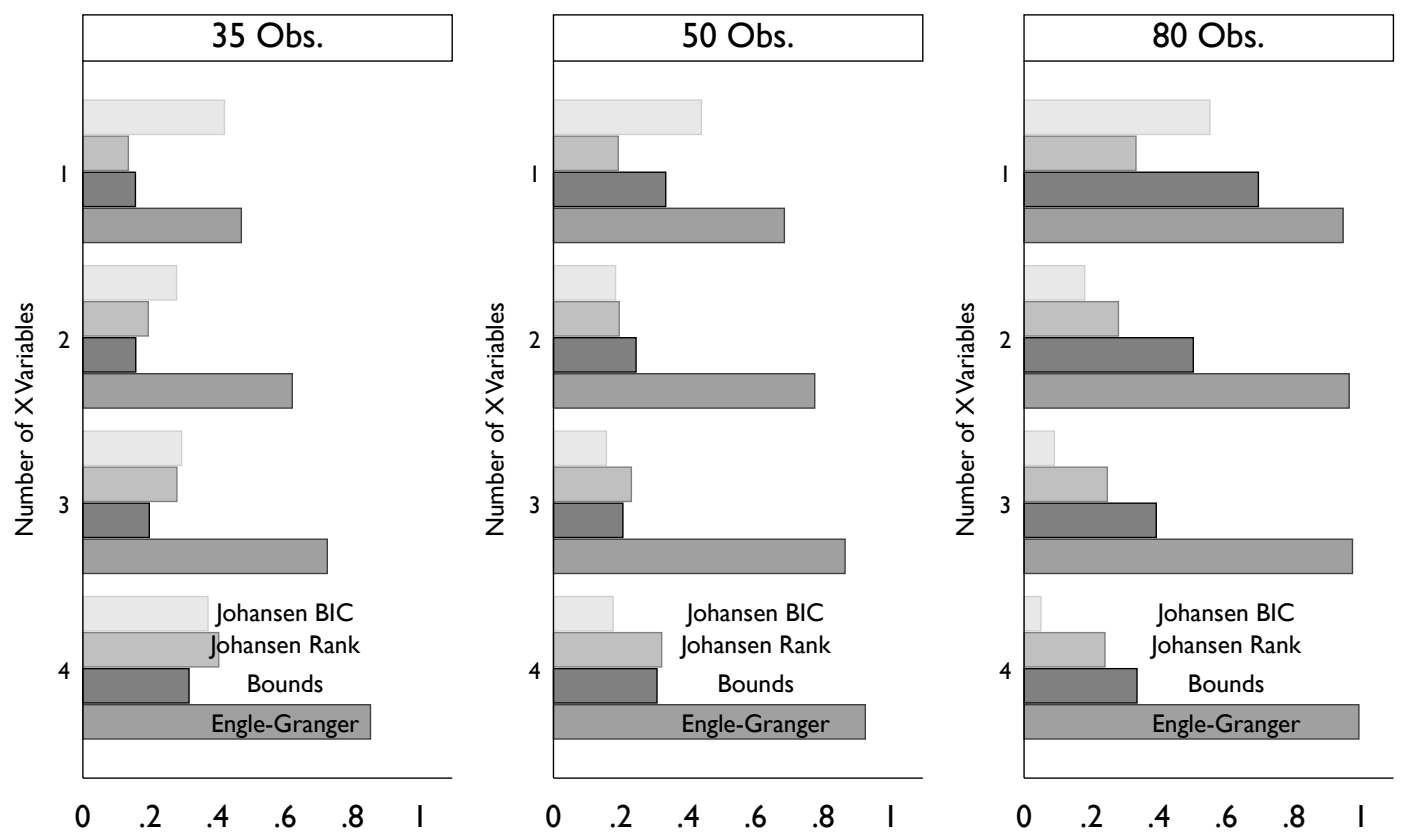

Proportion Finding Evidence of Cointegration at $<0.05$ Level

Johansen BIC $\square$ Johansen Rank $\square$ Bounds $\square$ Engle-Granger

Figure 4: Proportion of Monte Carlo Simulations (correctly) Detecting Cointegration 


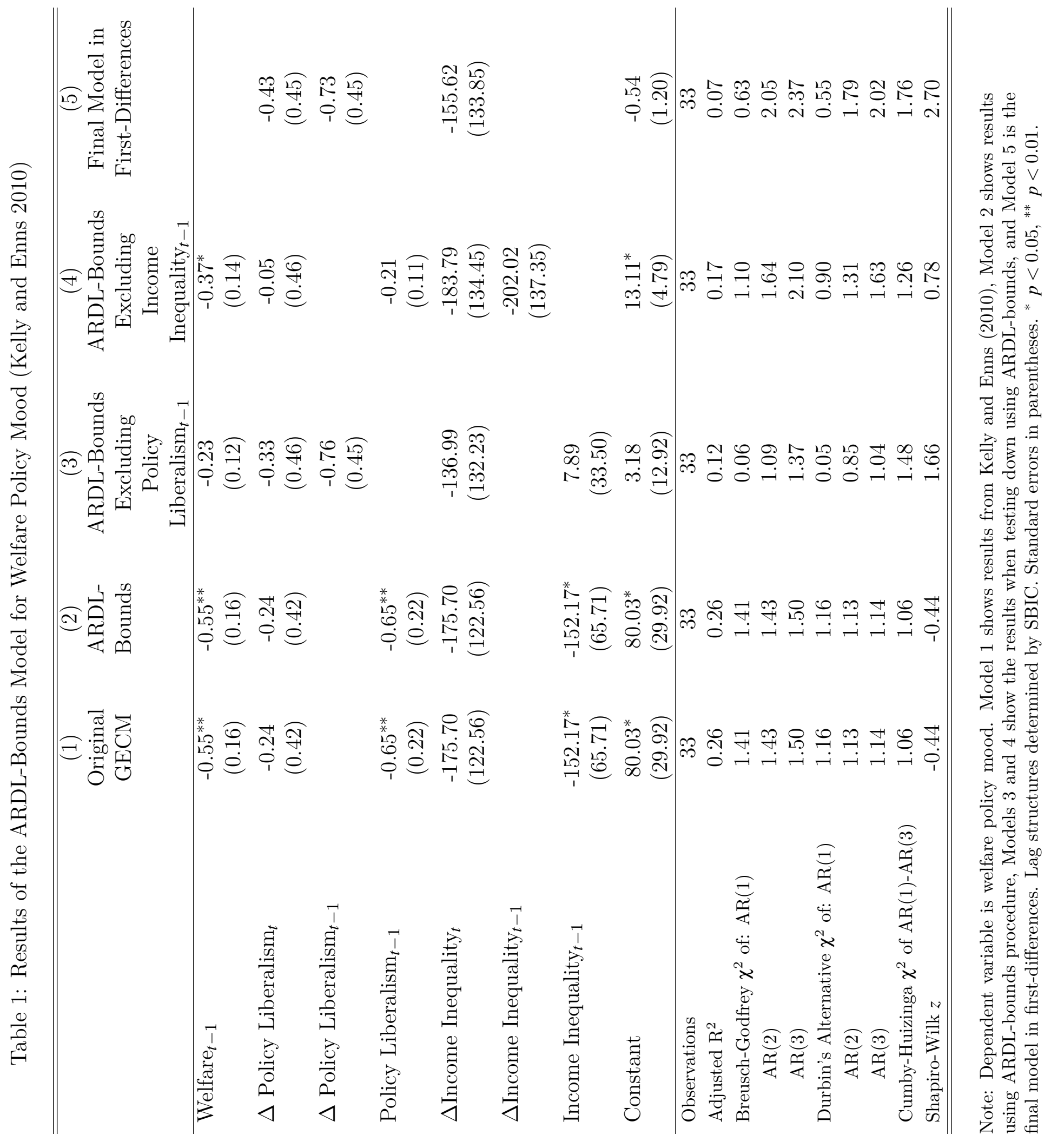


Table 2: Public Mood Towards Welfare is I(1) (Kelly and Enns 2010)

\begin{tabular}{lc} 
Unit-Root Test & Welfare \\
\hline \hline Augmented Dickey-Fuller (with drift) & $-2.05^{*}$ \\
Phillips-Perron & -1.94 \\
Dickey-Fuller GLS (with trend) & -2.55 \\
Elliott-Rothenberg-Stock & -2.55 \\
Kwiatkowski-Phillips-Schmidt-Shin $\left(H_{0}=\right.$ stationary $)$ & $0.49^{*}(\mathrm{no}$ lag $), 0.29$ (1 lag $)$ \\
\hline Conclusion: & $\mathrm{I}(1)$ \\
\hline
\end{tabular}

Note: $*=p<0.05$. 33 observations with 1-year lag included for all tests unless otherwise noted. $H_{0}=$ series contains a unit-root for all tests except KPSS. 
Table 3: Results of the ARDL-Bounds Model (Volscho and Kelly 2012)

\begin{tabular}{|c|c|c|}
\hline & $\begin{array}{c}(1) \\
\text { Original GECM }\end{array}$ & $\begin{array}{c}(2) \\
\text { ARDL-Bounds }\end{array}$ \\
\hline Top 1\% Share $_{t-1}$ & $-0.36^{* *}(0.09)$ & $-0.30^{* *}(0.07)$ \\
\hline$\Delta$ Democratic President $_{t}$ & & $1.47^{* *}(0.53)$ \\
\hline$\Delta$ Democratic President $_{t-1}$ & $0.14(0.56)$ & \\
\hline Democratic President $_{t-1}$ & $-0.20(0.36)$ & $0.11(0.34)$ \\
\hline$\Delta \%$ Congressional Democrat $_{t}$ & & $-0.03(0.04)$ \\
\hline$\Delta \%$ Congressional Democrat $_{t-1}$ & $0.05(0.04)$ & \\
\hline$\%$ Congressional Democrat $t_{t-1}$ & $-0.12^{* *}(0.04)$ & $-0.12^{* *}(0.03)$ \\
\hline$\Delta$ Divided Government $_{t}$ & & $0.37(0.46)$ \\
\hline$\Delta$ Divided Government $_{t-1}$ & $-0.11(0.50)$ & \\
\hline Divided Government $_{t-1}$ & $-0.93^{*}(0.42)$ & $-0.83^{*}(0.37)$ \\
\hline$\Delta$ Union Membership $_{t}$ & $0.29(0.28)$ & $0.04(0.28)$ \\
\hline Union Membership $t-1$ & $-0.11^{* *}(0.03)$ & $-0.09^{* *}(0.02)$ \\
\hline Constant & $15.05^{* *}(3.83)$ & $13.30^{* *}(2.81)$ \\
\hline Observations & 60 & 61 \\
\hline Adjusted $\mathrm{R}^{2}$ & 0.20 & 0.29 \\
\hline Breusch-Godfrey $\chi^{2}$ of: AR(1) & 1.39 & 3.19 \\
\hline $\operatorname{AR}(2)$ & 1.39 & 3.21 \\
\hline $\operatorname{AR}(3)$ & 2.79 & 5.03 \\
\hline Durbin's Alternative $\chi^{2}$ of: $\operatorname{AR}(1)$ & 1.16 & 2.76 \\
\hline $\operatorname{AR}(2)$ & 1.14 & 2.72 \\
\hline $\operatorname{AR}(3)$ & 2.29 & 4.31 \\
\hline Cumby-Huizinga $\chi^{2}$ of $\operatorname{AR}(1)-\operatorname{AR}(3)$ & 4.41 & 5.09 \\
\hline Shapiro-Wilk $z$ & 0.17 & 0.99 \\
\hline
\end{tabular}

Note: Dependent variable is the share of income of the top one percent. Model 1 shows results from Volscho and Kelly (2012) and Model 2 shows results using ARDL-bounds procedure, with lag structure determined by minimizing SBIC. Standard errors in parentheses. ${ }^{*} p<0.05,{ }^{* *} p<0.01$. 
Table 4: Top 1\% Share is I(1) (Volscho and Kelly 2012)

\begin{tabular}{lc} 
Unit-Root Test & Top 1\% Share \\
\hline \hline Augmented Dickey-Fuller (with drift) & 0.02 \\
Phillips-Perron & -0.21 \\
Dickey-Fuller GLS (with trend) & -1.35 \\
Elliott-Rothenberg-Stock & -1.35 \\
Kwiatkowski-Phillips-Schmidt-Shin $\left(H_{0}=\right.$ stationary $)$ & $2.20^{*}$ \\
\hline Conclusion: & $\mathrm{I}(1)$ \\
\hline
\end{tabular}

Note: $*=p<0.05 . T=60$ with 1-year lag included for all tests. $H_{0}=$ series contains a unit-root for all tests except KPSS. 